\title{
Ulasan Penelitian
}

\section{SISTEM HIDROPONIK NUTRIENT FILM TECHNIQUE (NFT) DAN WICK PADA PENANAMAN BAYAM MERAH}

\author{
Elvita Sari ${ }^{1}$, Yelina Kitty ${ }^{2}$, Astari Dwiranti ${ }^{3}$ \\ Department of Biotechnology and Neurology, Surya University \\ elvita.sari14@student.surya.ac.id,yelina.kitty14@student.surya.ac.id, astari.dwiranti@surya.ac.id
}

Indonesia terus mengalami peningkatan jumlah penduduk terutama dalam satu dekade terakhir. Hasil proyeksi Badan Pusat Statistik (BPS) menunjukkan bahwa jumlah penduduk Indonesia pada tahun 2020 akan mencapai 271,1 juta jiwa dan akan terus meningkat hingga 15 tahun mendatang (Bappenas et. al., 2013). Seiring dengan meningkatnya jumlah penduduk, permintaan pasar pada sektor pangan juga akan semakin meningkat (Roidah, 2014). Namun, hal tersebut tidak diikuti dengan ketersediaan lahan pertanian yang cukup. Penurunan luas lahan pertanian terutama pada sawah mencapai 0,25\% pada tahun 2013 (Pusat Data dan Sistem Informasi Pertanian, 2014). Keadaan ini yang menjadi landasan bahwa teknologi bercocok tanam dengan sistem hidroponik dapat diterapkan dalam masyarakat dan diharapkan dapat meningkatkan produksi bahan pangan terutama komoditas sayur-sayuran.

Sistem hidroponik merupakan salah satu cara menghasilkan produk tanaman terutama komoditas sayuran yang berkualitas tinggi secara berkelanjutan (Rosliani dan Sumarni, 2005). Sistem kultur secara hidroponik ini menerapkan metode penanaman tanaman tanpa menggunakan media berupa tanah (Rosliani dan Sumarni, 2005). Sehingga, budidaya tanaman dengan metode ini tidak memerlukan lahan yang luas. Selain itu, keuntungan dari penggunaan sistem ini dapat menghasilkan kuantitas dan kualitas produksi yang lebih tinggi dan bersih; penggunaan lahan lebih efisien; penggunaan pupuk dan air lebih efisien; serta periode tanam yang lebih singkat (Rosliani dan Sumarni, 2005). Teknologi sistem hidroponik dapat dibedakan menjadi beberapa jenis berdasarkan cara pemberian nutrisi. NFT (Nutrient Film Technique) dan wick merupakan contoh teknologi sistem hidroponik yang sederhana, mudah dibuat, dan minim mengakibatkan pembusukan tanaman (Hendra dan Andoko, 2014).

Sistem Nutrient Film Technique (NFT) merupakan teknik hidroponik dengan mengalirkan nutrisi dengan tinggi $\pm 3 \mathrm{~mm}$ pada perakaran tanaman. Sistem ini dapat dirakit menggunakan talang air atau pipa PVC dan pompa listrik untuk membantu sirkulasi nutrisi. Faktor penting pada sistem ini terletak pada kemiringan pipa PVC dan kecepatan nutrisi mengalir (Hendra dan Andoko, 2014). Penggunaan sistem NFT akan mempermudah pengendalian perakaran tanaman dan kebutuhan tanaman terpenuhi dengan cukup (Hendra dan Andoko, 2014). Sistem sumbu atau Wick System merupakan metode hidroponik yang memanfaatkan prinsip kapilaritas air. Larutan nutrisi mengalir ke 
media tanam melalui perantara sumbu. Sistem ini mudah dirakit dan mudah dilakukan untuk pemula (Hendra dan Andoko, 2014).

Penelitian ini menggunakan metode dengan sistem hidroponik Nutrient Film Technique (NFT) dan Wick System untuk penanaman tanaman bayam merah. Penelitian ini dilakukan pada proses penyemaian hingga pembuatan sistem hidroponik. Sistem hidroponik NFT dirancang menggunakan pipa PVC diameter 4 inch, pipa T, pipa L, penutup pipa, selang, container plastik dan pompa air. Sistem hidroponik wick berbahan dasar botol plastik bekas dan kain flanel sebagai sumbu. Media tanam yang digunakan pada proses penyemaian dan sistem hidroponik wick adalah sekam bakar, sedangkan pada sistem hidroponik NFT menggunakan rockwool. Bibit tanaman terlebih dahulu disemai dalam sekam bakar hingga muncul 2 helai daun. Rasio nutrisi AB mix pada sistem NFT dan wick adalah $5 \mathrm{ml}$ larutan stok A dan $5 \mathrm{ml}$ larutan stok B untuk 1 liter air. Panjang batang tanaman disetiap sistem diukur setiap harinya untuk mendapatkan perbandingan data.

Berdasarkan data pada sistem Nutrient Film Tehnique (NFT) diperoleh bahwa tanaman yang berada di lubang awal nutrisi masuk dan tanaman yang berada di lubang akhir nutrisi memiliki pertumbuhan yang bagus. Hal ini dikarenakan posisi tanaman dapat menjangkau nutrisi dengan baik. Pertumbuhan bayam merah juga dipengaruhi oleh penggunaan sumbu. Sumbu yang digunakan pada penelitian ini berasal dari kain bekas yang tidak terpakai lagi. Setelah dilakukan percobaan, bahan ini ternyata mudah rapuh dan jika disentuh sumbu tersebut hancur karena tidak tahan terlalu lama di dalam air yang berisi pupuk berkonsentrasi. Sumbu yang baik digunakan berasal dari kain flanel. Selain memiliki daya kapiler yang tinggi, kain flanel merupakan kain berserat yang tidak mudah rusak (Putera, 2015). Kekurangan juga terdapat pada pipa PVC yang digunakan pada rangkaian hidroponik NFT terlalu besar yaitu 4 inch sehingga ada beberapa netpot yang tidak mendapat aliran nutrisi cukup. Hal ini ditandai dengan beberapa permukaan rockwool yang kering. Pipa yang bagus digunakan adalah pipa PVC 3/4 dimensi (Hendra dan Andoko, 2014). Aliran nutrisi tidak merata. Hal ini dikarenakan saluran nutrisi yang dihantarkan melalui selang tidak seimbang sehingga ada beberapa tanaman yang mendapatkan nutrisi berlebihan, ada yang menggenangi, dan ada juga yang sedikit membasahi permukaan rockwool. Pada saat pengukuran setiap harinya, panjang tanaman diukur oleh peneliti yang berbeda. Hal ini menjadi penyebab pengukuran panjang tanaman menjadi tidak akurat karena setiap peneliti mempunyai cara mengukur yang berbeda-beda. Data pada sistem hidroponik wick menunjukkan hasil pertumbuhan tanaman bayam merah yang terus meningkat. Ini memperlihatkan bahwa hidroponik wick merupakan metode yang cukup bagus.

Sistem hidroponik NFT dapat diandalkan untuk produksi tanaman skala besar. Nutrisi pada sistem ini selalu mengalir sehingga seluruh netpot yang ada di dalam rangkaian mendapat nutrisi yang cukup. Sistem hidroponik NFT harus dirangkai dengan benar sehingga nutrisi dapat tersirkulasi dengan baik. Kelemahan dari sistem hidroponik NFT ini antara lain, ketersediaan dan pemeliharaan perangkat hidroponik agak sulit dan modal awal yang relatif lebih besar (Herwibowo dan Budiana, 2014). Selain itu membutuhkan lahan yang cukup besar dan bergantung pada ketersediaan listrik. 
Sistem metode wick ini mudah dalam perawatan terutama pemberian nutrisi yang dilakukan secara isi ulang pada pot penampung nutrisi sehingga tidak perlu terlalu sering dilakukan penyiraman (Nurwahyuni, 2013). Metode wick bisa digunakan untuk pemula atau hanya untuk sekedar hobi. Keunggulan dari sistem wick ini yaitu tidak membutuhkan perawatan khusus. Air dan nutrisi tanaman tidak mengalami sirkulasi sehingga tanaman akan terus-menerus mendapatkan suplai nutrisi. Namun, suplai nutrisi tersebut harus tetap diawasi agar tanaman tidak mengalami kekeringan. Penggunaan wadah yang tidak terlalu besar dan tidak menggunakan pompa air listrik membuat sistem wick mudah dipindahkan tanpa harus memikirkan ketersediaan listrik (Putera, 2015). Kelemahan dari sistem wick dalam penelitian ini adalah kurang bisa dihandalkan untuk produksi skala besar karena membutuhkan banyak wadah dan rumit dalam proses penambahan nutrisi untuk setiap wadah yang ada. Terutama ketika tanaman sudah mulai cukup besar dan membutuhkan banyak nutrisi.

\section{Endnotes}

${ }^{1}$ Mahasiswa Department of Biotechnology and Neurology, Surya University.

${ }^{2}$ Dosen Department of Biotechnology and Neurology, Surya University.

\section{Daftar Pustaka}

Bappenas, BPS, UNFPA. 2013. Proyeksi penduduk Indonesia 2010-2035. Jakarta: Badan Pusat Statistik.

Hendra, H. A., Andoko, A. 2014. Bertanam sayuran hidroponik ala paktani hydrofarm. Jakarta: AgroMedia Pustaka.

Herwibowo, K., Budiana, N. S. 2014. Hidroponik sayuran untuk hobi dan bisnis. Jakarta: Penebar Swadaya.

Nurwahyuni, E. 2013. Optimalisasi pekarangan melalui budidaya tanaman secara hidroponik. UNDIP PRESS, 863-868.

Pusat Data dan Sistem Informasi Pertanian. 2014. Statistik lahan pertanian tahun 2009-2013. Jakarta: Kementerian Pertanian.

Putera, T. D. 2015. Hidroponik Wick system. Jakarta: AgroMedia Pustaka.

Roidah, I. S. 2014. Pemanfaatan lahan dengan menggunakan sistem hidroponik. Jurnal Universitas Tulungagung Bonorowo 1 (2), 43-50.

Rosliani, R., Sumarni, N. 2005. Budidaya tanaman sayuran dengan sistem hidroponik. Bandung: Balai Penelitian Tanaman Sayuran. 